\title{
LAS NUEVAS EMPRENDEDORAS DE NEGOCIOS POR INTERNET ("NENIS") Y SU RELEVANCIA ECONÓMICA, SOCIAL Y MERCADOLÓGICA EN EL CONTEXTO DE LA PANDEMIA COVID-19 EN MÉXICO
}

\author{
THE NEW INTERNET BUSINESS ENTREPRENEURS ("NENIS") AND THEIR \\ ECONOMIC, SOCIAL AND MARKETING RELEVANCE IN THE CONTEXT OF THE \\ COVID-19 PANDEMIC IN MEXICO
}

\author{
Mireya Hernández-Ramírez ${ }^{1}$ * (D); Mireya Mojica-Hernández ${ }^{2}$ (D); Nadia Itayetzi Gómez-Morales ${ }^{3}$ (iD). \\ 1. Universidad Politécnica del Estado de Guerrero, México.mhernandez@upeg.edu.mx \\ 2. Universidad Nacional Autónoma de México, México.mireya.mojica.h@gmail.com \\ 3. Universidad Politécnica del Estado de Guerrero, México.nadia.gomez@upeg.edu.mx \\ *Autor de Correspondencia: Mireya Hernández-Ramírez, correo electrónico: mhernandez@upeg.edu.mx
}

\section{RESUMEN}

La coyuntura de la pandemia covid-19 ha significado pérdida de empleos en América Latina, principalmente entre el género femenino. Ante esta delicada situación, los emprendimientos han resurgido como una alternativa para mejorar la calidad de vida personal y familiar. Es el caso de las Nuevas Emprendedoras de Negocios por Internet ("Nenis"), cuya inserción ha permitido satisfacer necesidades básicas -y de otra índole-, lograr independencia económica, superación personal y empoderamiento, entre otros aspectos identificados en entrevistas y cuestionarios aplicados a diversos grupos de venta de esta naturaleza en México, ya que el emprendimiento propio les posibilita autoempleo para trabajar de forma libre sin depender de jefes ni exigencia de jornada laboral y dedicarse al cuidado de su hogar organizando la producción y/o distribución de sus bienes en horarios a conveniencia, utilizando estrategias básicas pero efectivas de mercadotecnia en redes sociales, mismas que se han convertido en grandes aliadas de las "Nenis" para acercar sus productos a los consumidores y concretar ventas, logrando con ello una inclusión relevante en los ámbitos económico, social y mercadológico de su localidad. Así, con su actuar de fortaleza y resiliencia, son parte esencial de la reactivación económica durante la actual emergencia sanitaria del país.

Palabras claves: nuevas emprendedoras; negocios por internet; nenis; COVID-19.

Cómo citar:

Hernández-Ramírez, Mireya; Mojica-Hernández, Mireya; Gómez-Morales, Nadia Itayetzi. (2021). Las nuevas emprendedoras de negocios por internet ("nenis") y su relevancia económica, social y mercadológica en el contexto de la pandemia Covid-19 en México. Revista de Investigaciones Universidad del Quindio, 33(S1), 225-239. https://doi.org/10.33975/riuq.vol33nS1.495 


\begin{abstract}
The situation of the covid-19 pandemic has meant job losses in Latin America, mainly among the female gender. Faced with this delicate situation, businesses have re-emerged as an alternative to improve the quality of personal and family life. This is the case of the New Internet Business Entrepreneurs ("Nenis"), whose insertion has made it possible to satisfy basic needs -and other kinds-, achieve economic independence, personal improvement and empowerment, among other aspects identified in interviews and questionnaires applied to various sales groups of this nature in Mexico, since their own entrepreneurship allows them self-employment to work freely without depending on bosses or the requirement of working hours and dedicate themselves to taking care of their home, organizing the production and / or distribution of their goods in schedules at convenience, using basic but effective marketing strategies in social networks, which have become great allies of the "Nenis" to bring their products to consumers and make sales, thereby achieving a relevant inclusion in the economic sphere, social and marketing of your locality. Thus, with their actions of strength and resilience, they are an essential part of the economic reactivation during the current health emergency in the country.
\end{abstract}

Keywords: new entrepreneurs; internet businesses; nenis; COVID-19.

\title{
INTRODUCCIÓN
}

En coyunturas de crisis económicas severas, los emprendimientos en pequeña escala suelen representar una alternativa asequible para las personas que se encuentran en circunstancias de desempleo. De esta manera, la cultura del emprendimiento es benéfica ya que impulsa a la economía doméstica, máxime cuando la oferta laboral se reduce gravemente. Dicha situación se ha observado a raíz de la actual pandemia covid-19, lo que ha significado mayores afectaciones en términos de despidos o desocupación de mujeres en comparación con los hombres en América Latina, ubicándolas con ello en una posición vulnerable y en la necesidad de atender tanto nuevos riesgos como desafíos para mantenerse a sí mismas, cuidar a su familia e inclusive tolerar climas de violencia en sus propios hogares.

Ante este panorama de incertidumbre, mujeres emprendedoras de la República Mexicana tomaron la decisión de incorporarse al mercado en la producción y/o distribución de bienes elaborados por ellas mismas o provenientes de empresas establecidas, con la finalidad de promoverlos y comercializarlos a través de medios digitales. En la mayoría de los casos, el capital que tienden a invertir es reducido y ello les da cierto margen de maniobra para obtener ganancias a corto plazo, de las cuales una parte la destinan a su consumo personal y/o familiar, y otra a la reinversión para adquirir materias primas, bienes intermedios o finales, según sea el caso.

A fines del mes de febrero del presente año 2021, pudimos observar que en México se volvió viral en redes sociales el término "Nenis", utilizado en sus inicios para estigmatizar o demeritar la labor de estas mujeres emprendedoras en virtud de que en sus estrategias de venta utilizan palabras de halago hacia sus clientas: "nena", "hermosa", "guapa", "preciosa", "bella", etc., que complementan con frases persuasivas como: "sólo me quedan algunos productos", "es la última pieza que tengo", "voy a cerrar pedido", entre otras. 
No obstante, a inicios de marzo de 2021, diversos usuarios de redes sociales y las propias "Nenis" reivindicaron el término al otorgarle otra connotación: "Nuevas Emprendedoras de Negocios por Internet”, destacando así la relevancia de su rol en la economía personal, familiar y de su localidad.

En términos generales, las "Nenis" utilizan técnicas de contabilidad sencillas para llevar sus controles de ingresos y egresos, de sus inventarios y principalmente de actividades orientadas al mercadeo, ya que son: publicistas en redes sociales, diseñadoras de productos, agentes de ventas para negociar y cerrar pedidos, creadoras de su propia logística, mensajeras para servicios de entrega, etc.

\section{MARCO TEÓRICO}

\section{- Definiciones de Emprendimiento}

El concepto de "emprendimiento" proviene del francés entrepreneur, el cual “... significa 'pionero' y hace referencia a la capacidad que posee una persona para desarrollar un esfuerzo significativo por lograr una meta" (Raffino, 2020).

En la actualidad, este término hace referencia a una nueva empresa o proyecto inicial de una persona, o bien, de un grupo de personas.

Por otra parte, el emprendedor es el individuo que enfrenta el desafío de un nuevo negocio o proyecto que es realizado sorteando numerosas dificultades, con la finalidad de obtener un beneficio económico (Raffino, 2020).

De esta forma, cuando el emprendedor toma la decisión de independizarse y trabajar por cuenta propia para modelar su propio negocio, a la par que renuncia a la estabilidad que implica obtener un salario seguro, se desenvuelve bajo un esquema de riesgo e incertidumbre pero con la expectativa de identificar, aprovechar y maximizar la oportunidad existente en el mercado del bien que ha decidido producir y/o comercializar.

\section{- Tipos de Emprendimiento}

En el contexto de la presente investigación y tomando como referencia los Tipos de Emprendimiento de Raffino (2020), aquellos promovidos por las Nuevas Emprendedoras de negocios por internet encuadrarían en la siguiente tipología:

- Emprendimientos pequeños. Son aquellos negocios a pequeña escala liderados por una o más personas con el fin de producir o distribuir un bien o un servicio. Las ganancias generadas son empleadas para cubrir los requerimientos del propio negocio y sostener el coste de vida del emprendedor.

- Emprendimiento por necesidad. Estos negocios surgen cuando el individuo está en la búsqueda de una nueva forma de generar ingresos económicos, es decir, obedecen a la propia necesidad del emprendedor.

- Emprendimientos por oportunidad. Hace referencia a Negocios que surgen al observar una necesidad en el mercado. 
- Emprendimientos digitales. Se definen como negocios que se realizan a través de internet, esto es, los productos se promueven en redes sociales, páginas web o electrónicas, etc.

- Emprendimiento espejo. Negocios que imitan o se basan en la producción de un bien o servicio que ya existe. Algunos pueden ser idénticos, otros símiles y otros más, un tanto modificados.

\section{- Nuevas Emprendedoras de Negocios por Internet ("Nenis"):}

En la última semana del mes de febrero del presente año 2021, comenzó a hacerse viral la palabra "Nenis" para conceptualizar así a las mujeres que se auto-emplean por diversas razones en la modalidad de negocio de tipo minorista, ya sea para producir y/o comercializar categorías de bienes que en la actualidad son demandados por los consumidores, los cuales son promovidos en redes sociales. En su mayoría, las "Nenis" son mujeres jóvenes y adultos jóvenes que durante la emergencia sanitaria se quedaron sin empleo, o bien, no laboraban pero se vieron en la necesidad de identificar alguna fuente de ingresos para sus hogares. En su oferta de productos destacan alimentos, ropa nueva o usada, cosméticos y accesorios, los cuales entregan en puntos específicos céntricos o intermedios con respecto a su lugar de residencia y el del cliente, o bien a completa conveniencia de este último, inclusive con servicio a domicilio. Los envíos a otras ciudades las categorizan como "Neni premium" (Milenio, 2021), lo cual puede observarse en la Imagen 2:

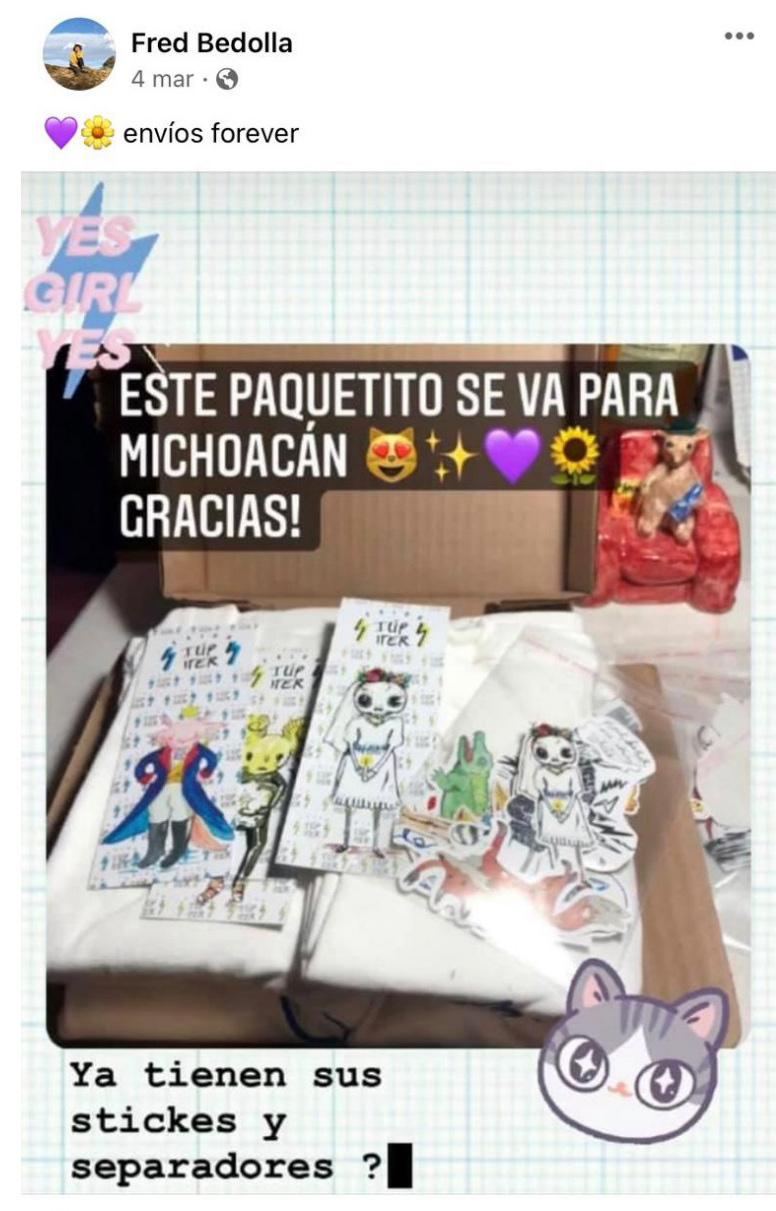

1032
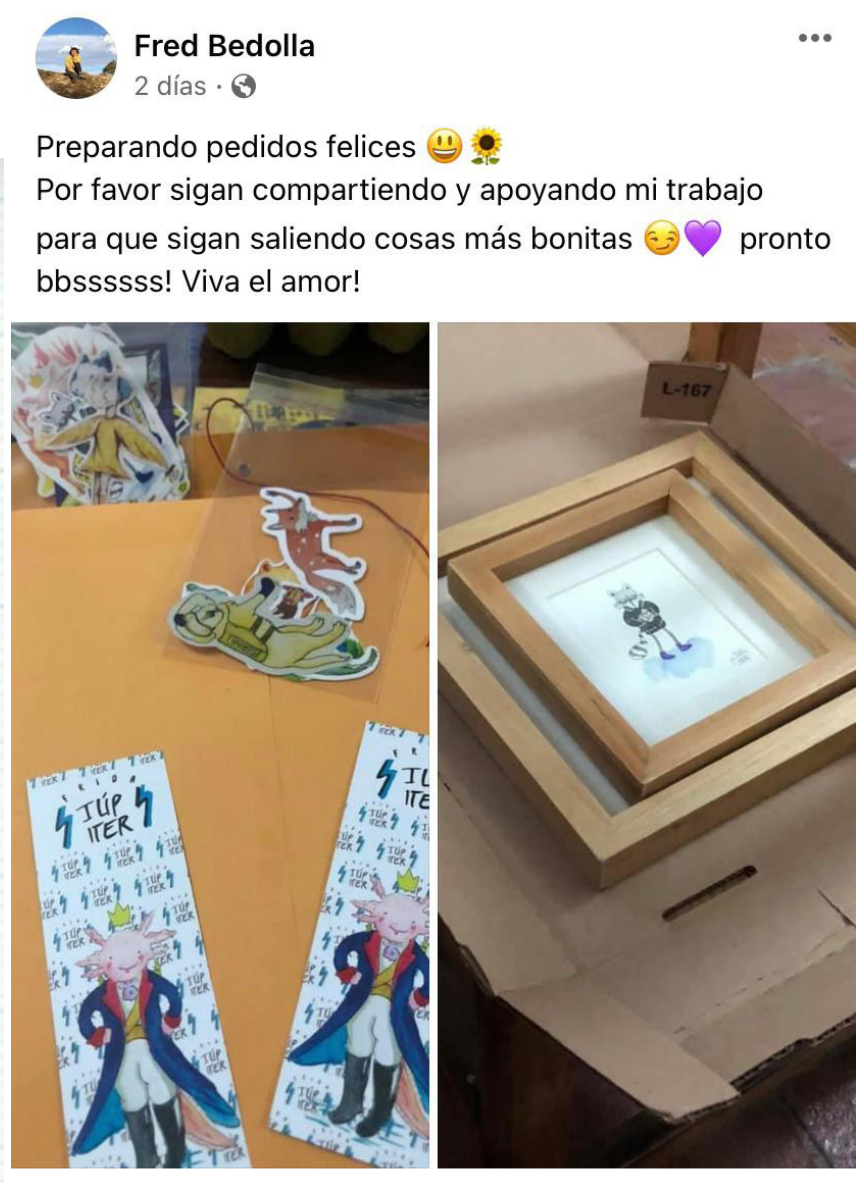

(1) 22

Imagen 2. Publicación de "Neni premium". 


\section{PROBLEMÁTICA}

De acuerdo a la información del periódico La Jornada (2021), aunado al rezago que ya existía de tiempo atrás en la inclusión laboral de las mujeres, durante el año 2020 la pandemia covid-19 provocó un incremento en la salida del mercado de trabajo de este género en México: cifras del Instituto Nacional de Estadística, Geografía e Informática (INEGI, 2021) refieren que aproximadamente 1.3 millones de mujeres perdieron su empleo el año pasado.

A su vez, el diario La Jornada (2021) señala que en el empleo formal las mujeres ganaban en promedio 54.1 pesos menos que los hombres durante el año 2020, lo cual evidencia la brecha laboral y salarial existente entre ambos géneros. Más de la mitad de los trabajadores en México se ocupan por menos de dos salarios mínimos, pero estos empleos de bajos ingresos son a los que más tienen acceso las mujeres. El INEGI (2021) muestra que siete de cada 10 trabajadoras en México se ocupan por menos de dos salarios mínimos, mientras en los hombres la proporción es seis de cada 10.

En este contexto, la brecha salarial en México continúa siendo una cuenta pendiente con las mujeres que laboran, ya que con base en datos de la Secretaría del Trabajo y Previsión Social (STPS), éstas reciben una remuneración 12.6 por ciento menor que los varones a escala nacional y en algunas entidades ese porcentaje es mayor (Milenio, 2021).

Acorde con la Organización para la Cooperación y el Desarrollo Económicos (OCDE), se puede entender como brecha salarial a la diferencia porcentual que existe entre las retribuciones salariales que perciben hombres y mujeres, pero medidas en relación al salario masculino. Se reitera que este es un problema que ha estado vigente por años y en diversos lugares del mundo incluida Latinoamérica, pero lo preocupante es que México es el país de esta región que se encuentra más lejos de cerrar la brecha salarial de género. En promedio, los ingresos percibidos por las mujeres representan apenas un $46 \%$ con respecto al de los hombres (Merca2.0, 2021).

Por su parte, el Centro de Estudios para América Latina y el Caribe (El Financiero, 2021), señala que cuando se compara el salario de un hombre y una mujer que forman un hogar, y trabajan las mismas horas a la semana, la diferencia se amplía en contra de las mujeres en función del número de niños que se encuentren en casa, debido a los cuidados que demandan, no sólo por su edad, sino también porque es importante recordar que durante el confinamiento los infantes han estado recibiendo clases en la modalidad a distancia, a través de medios tecnológicos, lo cual evidencia que mientras más niños hay en casa, menor será la oportunidad de la mujer para acceder a más horas de trabajo; ocurre algo similar cuando hay adultos mayores o personas con discapacidad, que en su mayoría son cuidados por mujeres. Todo ello, catalogado como la "economía del cuidado", es considerado una "sobrecarga" de trabajo para las mujeres, que además no le es remunerada.

Otro estudio realizado por la UNAM (2021) menciona que, derivado de los decretos del 23 y 30 de marzo de 2020, publicados en el Diario Oficial de la Federación (DOF) en los que se determinó cuáles eran consideradas actividades esenciales durante la emergencia sanitaria, se produjo el cierre de 75 por ciento de comercios en México y esto afectó la economía de una cantidad importante de mujeres, quienes tuvieron que buscar otras formas de obtener ingresos. 


\section{OBJETIVO GENERAL}

- Destacar la relevancia económica, social y mercadológica de las Nuevas emprendedoras de negocios por internet ("Nenis") durante la pandemia covid-19 en México.

\section{OBJETIVOS ESPECÍFICOS:}

- Definir el término Emprendimiento.

- Identificar los Tipos de Emprendimiento vinculados a las Nuevas emprendedoras de negocios por internet ("Nenis") en México.

- Precisar características económicas específicas de las "Nenis": tipos de bienes producidos y/o comercializados, principales medios de pago, ganancias y su destino, impacto en la economía mexicana, entre otras.

- Enfatizar la conceptualización social de las Nuevas emprendedoras de negocios por internet: características o perfil de las "Nenis", edad, nivel educativo, rol en "economía del cuidado", etc.

- Resaltar las estrategias de Mercadotecnia de las "Nenis": tipo de productos y comercialización de bienes o logística, usos de medios digitales, técnicas de venta, atención al cliente, etc.

\section{JUSTIFICACIÓN}

En medio de la problemática ya expuesta, encontramos a mujeres jóvenes que estudian con el apoyo económico o sostenimiento de sus padres (quienes en algunos casos se quedaron sin empleo durante la pandemia covid-19), pero también a mujeres jóvenes y en la tipología de adultos jóvenes que, debido al confinamiento, tuvieron que buscar alternativas para la obtención de ingresos que les permitiera manejarse en el esquema de la economía del cuidado en casa, con niños -en clases virtuales-, adultos mayores, personas con discapacidad, etc. Es en este contexto en el que comienza a destacar la participación activa de la "economía neni", que engloba a las nuevas mujeres emprendedoras de negocios por internet, quienes detectaron en el comercio minorista en línea la oportunidad para autoemplearse de manera independiente.

Lo anterior vino a complementarse con la existencia de “...empresas con un gran inventario de productos disponibles para que vendedores, en su mayoría mujeres, se dediquen a comerciar al menudeo" (UNAM, 2021). Recordemos que, durante el confinamiento, diversas empresas productoras de bienes considerados no esenciales han tenido problemas para desplazar sus mercancías de manera presencial, tal y como lo habían venido haciendo hasta antes de la emergencia sanitaria.

“...dicha modalidad crea empleo para tres personas, comenzando con una empresa que le vende a una emprendedora cierto producto y ésta a su vez lo ofrece a alguien más a través de catálogos o de manera física" (UNAM, 2021).

Por supuesto, es importante considerar que si bien hay mujeres que ya tenían sus emprendimientos en la elaboración de sus propios productos, también hay quienes los han iniciado en esta coyuntura; en ambos casos la comercialización principal ha sido a través de redes sociales. Con respecto a este punto, encontramos otro aspecto interesante que se refiere al consumo de medios digitales, ya que previo al covid, en México era de 2.57 horas y durante el covid-19 se ha incrementado a 4.12 horas. De esta manera, el uso de redes sociales aumentó en un 30\% durante esta emergencia sanitaria, destacando Facebook y Whatsapp, entre las diversas aplicaciones (Nielsen-IBOPE-México, 2021). 


\section{HIPÓTESIS}

Durante la pandemia covid-19 el desempleo femenino aumentó de manera preocupante en América Latina; para el caso particular de México ha representado la oportunidad de emprendimientos para mujeres denominadas las Nuevas emprendedoras de negocios por internet ("Nenis"), insertándolas de forma relevante en el contexto económico, social y mercadológico de su entorno.

\section{MÉTODO}

Método deductivo: en el contexto general de desempleo principalmente de mujeres en América Latina durante la presente contingencia sanitaria, se identificó que en el ámbito particular de México aumentaba la presencia y participación de este género en la modalidad de emprendimientos con ventas mediante el uso de redes sociales (Nenis), sobre todo en los últimos meses.

Investigación de tipo mixto: se detectaron y estudiaron diferentes aspectos o características tanto cualitativas como cuantitativas de las "Nenis", en los ámbitos económico, social y mercadológico.

Investigación Documental: se procedió a la revisión del estado del arte del tema en cuestión en diversos materiales impresos y digitales, principalmente en lo que respecta a tópicos de Emprendimiento y sus tipos, así como actualidades de la economía en el contexto "neni", de "cuidado" y temas afines.

Análisis-Síntesis: también estuvieron presentes a lo largo de la investigación al revisar, analizar e interpretar a detalle información relevante para incluirse en este trabajo.

\section{Investigación Directa o de campo:}

- Técnica de Observación: para analizar minuciosamente tanto el comportamiento de las "Nenis" durante la actual emergencia sanitaria, así como sus actividades, aptitudes, actitudes y reacciones en las estrategias de mercadeo, para la promoción y comercialización de sus productos.

- Cuestionarios y Entrevistas, cuyo procedimiento de aplicación se explicará enseguida en la Muestra:

\section{Muestra}

Para recolectar los datos, la investigación se dividió en dos etapas:

En la primera se identificaron grupos cerrados y abiertos de ventas de diversos productos por internet, para identificar a las mujeres "Nenis", a las cuales se les aplicó un instrumento de recolección de datos digital (cuestionario), con la finalidad de precisar sus características o variables económicas, sociales y mercadológicas, con un alcance de 1000 mujeres "Nenis" que radican en la Ciudad de México y en otras ciudades importantes de algunas entidades federativas de la República Mexicana entre las que destacan: Guerrero, Morelos, Jalisco, Nayarit, Veracruz, Baja California, Tabasco, Aguascalientes, Querétaro, Puebla, Nuevo León, Estado de México y Yucatán.

En la segunda etapa se entrevistaron a informantes clave ya sea administradores de estos mismos grupos de venta o algunos de sus miembros, para profundizar en las variables económicas, sociales y mercadológicas, mismas que se precisan en las últimas secciones de este trabajo. 


\section{Criterios de inclusión y de exclusión para selección de la Muestra:}

\section{- Criterios de inclusión:}

1. Mujeres emprendedoras de 15 años de edad o más, que efectúen ventas de productos por redes sociales.

2. Mujeres "Nenis" integradas a grupos de ventas cerrados y abiertos.

3. Mujeres "Nenis" con entregas a domicilio, en puntos específicos y/o envíos.

4. Lugar de residencia: República Mexicana.

\section{- Criterios de exclusión:}

1. Hombres emprendedores de cualquier edad, que realicen ventas por redes sociales.

2. Mujeres que tengan locales propios o rentados para la venta de sus productos.

3. Mujeres menores de 15 años.

4. Mujeres "Nenis" cuya residencia se ubique fuera de la República Mexicana.

\section{HALLAZGOS}

De acuerdo a las técnicas utilizadas para la obtención de datos, los hallazgos de la muestra antes enunciada fueron los siguientes:

- Edad: el rango predominante fue el de 20 a 24 años (25\%), seguida de la cifra abierta de 40 y más (22.1\%), posteriormente el de 25 a 29 años (20.7\%), de 35 a 39 años (11.4\%), de 30 a 34 años (10.8\%) y por último de 15 a 19 años $(10 \%)$.

- Nivel de estudios: Licenciatura (58.2\%), Preparatoria (24.8\%), Posgrado (9.2\%), Secundaria (7.1\%) y Primaria $(0.7 \%)$, tal y como puede apreciarse en la Gráfica 1:

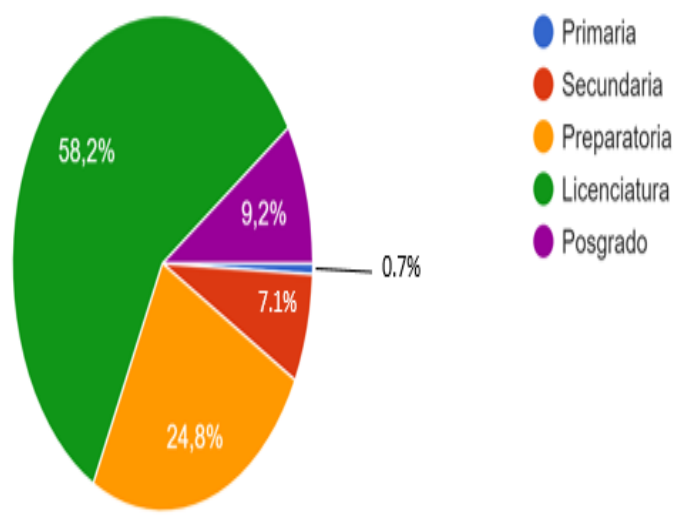

Gráfica 1. Nivel de estudios.

- Estado civil: Soltera (54.3\%), Casada (22.9\%), Unión libre (15\%), Divorciada (5\%) y Viuda $(2.8 \%)$.

- Número de hijos: Sin hijos (55.7\%), un hijo (14.3\%), dos hijos (20.7\%), tres hijos (8.6\%), 4 hijos o más $(0.7 \%)$.

- En orden de importancia los bienes que más producen y/o comercializan, son: Alimentos y bebidas; ropa nueva, joyería y cosméticos; ropa usada y accesorios para vestir; cubre-bocas y artículos de salud; manualidades; calzado; productos para el hogar; juguetes; accesorios para celulares; libros; 
productos biodegradables; complementos nutricionales; servicios (Marketing, lavandería, entre otros).

- Número de horas a la semana dedicadas al emprendimiento: de 3 a 5 horas (48.6\%); de 6 a 8 horas (28.6\%); de 9 a 11 horas (4.2\%) y 12 horas o más (18.6\%).

$\cdot$

- Personas que dependen económicamente de las "Nenis": 55.3\% de las encuestadas señalaron que tienen al menos una persona (de 1 a 3 personas o más) que depende económicamente de ellas; $y$ $44.7 \%$ de las encuestadas respondieron que ninguna persona depende económicamente de ellas, tal y como se aprecia en la Gráfica 2:

\section{¿Cuántas personas dependen económicamente de ti? 141 respuestas}

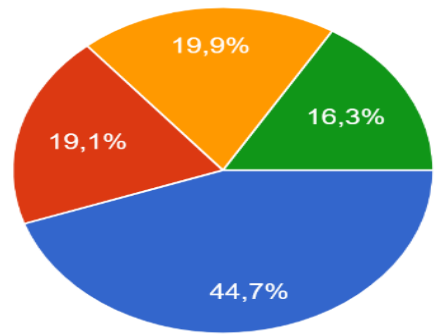

Ninguna persona depende económicamente de mí

1 persona

2 personas

3 personas o más

Gráfica 2. Porcentaje de personas que dependen económicamente de las "Nenis".

- El 60\% de las encuestadas se considera económicamente independiente y el 40\% no se considera así.

- Acerca de la utilización de redes sociales y/o aplicaciones, los cuestionarios arrojaron que las "Nenis" emplean más de un medio digital para promover y comercializar sus productos. En este sentido, las de mayor uso entre el total de la muestra encuestada resultaron: Facebook, Whatsapp e Instagram. En primer término, la más utilizada fue Facebook, ya que un $82.3 \%$ de todas las encuestadas refirió usar esta red social; en segundo lugar, Whatsapp con el 78\% del total de las participantes que expresaron emplear esta aplicación; en tercer lugar se ubicó Instagram con el $38.3 \%$ de la totalidad de las encuestadas que manifestaron utilizar esta red; lo anterior puede observarse en la Gráfica 3:

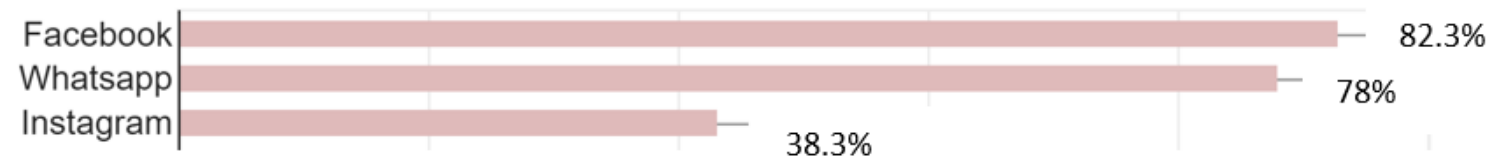

Gráfica 3. Redes sociales más utilizadas por las "Nenis".

- En cuanto a las entregas a domicilio, el $61.4 \%$ sí las realiza y el $38.6 \%$ restante, no.

- Número de puntos de entregas de sus productos: de 1 a 3 puntos de entrega (77\%); de 4 a 6 puntos de entrega $(14.6 \%)$ y de 7 ó más puntos de entrega ( $8 \%)$.

- El 38.6 \% realiza envíos fuera de su ciudad ("Nenis premium") y el $61.4 \%$, no.

- El 75\% de las encuestadas expresó tener ganancias mensuales entre $\$ 3,000$ a $\$ 5,000$ (pesos mexicanos), y el 25\% restante señaló ganar más de $\$ 5,000$ al mes.

- Acerca del término "neni", el 67.1\% expresó que reconoce a la mujer emprendedora, y el 32.9\% opinó que es despectivo.

- En la pregunta acerca de medios de pago, las "Nenis" refirieron aceptar diferentes modalidades: en primer lugar destacó el uso de efectivo, ya que el 92\% del total de las encuestadas declaró 
admitirlo; en segundo término se ubicó el empleo de transferencias o depósitos bancarios cuya cifra se colocó en $75.7 \%$; finalmente, el $7.1 \%$ de la totalidad de la muestra expresó aceptar el trueque.

- El 76.4\% sí tiene un registro de sus ingresos y egresos, mientras que el 23.6\% no.

- Del dinero invertido mensualmente en su emprendimiento, el 83\% señaló que destinan de $\$ 2,000$ a $\$ 4,000$ y el $17 \%$ restante señaló que más de $\$ 4,000$ al mes.

- Acerca del origen del dinero para invertir en su emprendimiento, las cifras obtenidas fueron: no recibo ningún tipo de apoyo (58.9\%); préstamo de familiares o amigos (27.7\%); donativo de familiares o amigos (6.3\%); crédito bancario o de otra institución financiera (4.3\%); apoyo gubernamental $(2.8 \%)$.

- El origen de su emprendimiento fue debido a la pandemia covid-19: el 61\% respondió que sí y el $39 \%$ que no.

- Acerca de las razones por las cuales iniciaron su emprendimiento, las encuestadas expresaron: para tener ingresos necesarios y enfrentar la pandemia: $67.1 \%$; para ser mi propia jefa: $14.3 \%$; pérdida de trabajo: 7.9\%; para estar en casa al cuidado de la familia: 10.7\%

- En cuanto a la pregunta sobre la utilización o destino de sus ganancias, las respuestas fueron: $65.2 \%$ utiliza sus ganancias en gastos familiares del hogar (alimentos, ropa, estudios y servicios); $13.4 \%$ lo canaliza al ahorro; $8 \%$ lo orienta a diversiones; $7.1 \%$ lo dirige a pago de deudas y el $6.3 \%$ a gastos médicos.

Entre los comentarios recogidos de los instrumentos para recolección de datos Cuestionario digital y Entrevistas, destacan los siguientes:

Algunas mujeres han sufrido discriminación en redes sociales por su tipo de actividad, asaltos y recepción de billetes falsos en sitios de entrega, inseguridad por perfiles falsos, incertidumbre con respecto a si el usuario tiene o no la intención de compra. Señalaron que iniciar este tipo de emprendimiento puede resultar difícil y frustrante al inicio, cierto desgaste físico y mental cuando venden a crédito, regateo persistente por parte del cliente, comentarios dolosos de sus propios familiares y/o amistades que demeritan su trabajo, ventas cíclicas, etc.

No obstante, la mayoría expresó su satisfacción hacia su emprendimiento ya que les resulta gratificante ver cómo se incrementa su número de contactos y con ello el reforzamiento de sus vínculos inclusive de amistad con clientes específicos y, por supuesto, sus ventas y ganancias.

Por último, señalaron que la experiencia es enriquecedora ya que conforme pasa el tiempo, sus ventas se vuelven más estables y se reactivan sus finanzas personales; no desean retomar trabajos anteriores ni tener jefes sujetándolas a horarios que resultan en jornadas laborales largas que no compensan su esfuerzo.

\section{DISCUSIÓN}

De acuerdo a informes del Banco Mundial (2021), las condiciones de desigualdad laboral de mujeres y hombres se han agudizado ante la emergencia sanitaria.

Durante el año 2020, en América Latina se perdieron 30 millones de empleos, principalmente de mujeres (BID, 2021), y específicamente en México la cifra fue de 1.3 millones de mujeres (INEGI, 2021). 
Sin duda alguna, la pandemia covid-19 ha afectado más a mujeres que hombres en términos de pérdida de empleo en actividades consideradas no esenciales, o en circunstancias de renuncia al mismo debido al contexto del confinamiento en un esquema de atención de hijos en casa ya sea por el cierre de guarderías (en el caso de los pequeños), de niños que toman sus clases por medios electrónicos, en la atención de adultos mayores, etc., que implican "economía del cuidado", lo cual no le es remunerado a las mujeres en las circunstancias antes descritas. No obstante, las mujeres están intentando romper con estereotipos de roles tradicionales y/o de complementar los actuales en forma más equitativa.

\section{CONCLUSIONES}

\section{Características o variables económicas:}

En la mayoría de los empleos en México, las mujeres carecen de seguridad social (IMSS, prestaciones, derecho a pensión, etc.), y por ello requieren actividades que les redunden beneficios económicos en condiciones de bienestar. Así, la actual coyuntura covid-19 ha sido maximizada como oportunidad por parte de las mujeres que integran la llamada "economía Neni", cuya capacidad resiliente y la propia necesidad las ha motivado a auto-emplearse en este esquema, aun con riesgo de contagio; buscando protegerse y sanitizarse lo más posible, acuden a puntos específicos para la entrega de sus productos aceptando como medio de pago principal el efectivo (dinero), pero también transferencias bancarias e incluso trueque.

De esta forma, con sus ingresos adicionales obtenidos a través de la venta de sus productos, algunos elaborados en casa y otros adquiridos como bienes finales para su distribución, las "Nenis" contribuyen a la reactivación económica generando con ello un impacto local de sus emprendimientos, que trasciende su importancia en las entidades federativas a las que pertenecen.

Si bien es cierto que las ganancias son a corto plazo y existe la necesidad inmediata de destinar una parte al consumo personal/familiar y otra a la reinversión de sus negocios, se reitera que el estudio reciente efectuado por la UNAM (2021), refiere que la "economía neni” genera 9.5 millones de pesos diarios por concepto de ventas en la República Mexicana y que su importancia ha aumentado ya que alrededor de 13 millones de hogares de nuestro país tienen ingresos debido a este tipo de comercio.

En efecto, los cuestionarios y entrevistas de la presente investigación arrojaron que el 61\% de las Nenis iniciaron su negocio debido a la emergencia sanitaria para obtener ingresos suficientes que les permitan enfrentarla; al respecto la mayoría refirió que el $65.2 \%$ de sus ganancias mensuales que oscilan de 3 mil a 5 mil pesos mexicanos, las destinan a gastos familiares del hogar.

\section{Características o variables sociales:}

Las "Nenis" se autodefinen como mujeres creativas, entusiastas, talentosas, con adaptación al cambio, perseverantes, capaces de enfrentar riesgos, pacientes, informadas del acontecer cotidiano, útiles en su entorno al aportar dinero a su economía familiar y local. Además, quienes han perdido su empleo se reconocen con empoderamiento suficiente para ser su propio "jefe" y no retornar a la subordinación de jornadas laborales largas y agotadoras, con remuneración que no compensa su esfuerzo. El confinamiento les ha abierto la oportunidad de tener mayor tiempo para el cuidado de sus familiares e incluso de recibir el apoyo de miembros de la propia familia en sus actividades de emprendimiento, lo cual les da pauta para interactuar más tiempo y en espacios compartidos con sus seres queridos, a quienes definen como su "motivación principal". 
Acorde a la investigación, las "Nenis" son principalmente mujeres jóvenes y adultos jóvenes en las que predomina el nivel licenciatura, cuyas aspiraciones propias son fuente de inspiración para los emprendimientos y se traducen en ejemplos para otras mujeres ya que se visibilizan como referentes reales, expresándose como mujeres empoderadas en perspectiva económica y social.

\section{Características o variables mercadológicas:}

Hoy en día, las mujeres están más conectadas que nunca en dispositivos digitales, pendientes al 100\% de sus negocios; el confinamiento ha representado la posibilidad de cambios en diversos aspectos: en términos de ingresos, como ya se mencionó anteriormente, pero también en aspectos de tecnología.

Cabe señalar que las "Nenis" se organizan en redes de negocios, no se ven como competencia, colaboran entre mujeres, respetan la equidad de género, se dan consejos mutuos, incorporan a más miembros, se recomiendan para adquisición de productos incluso símiles (sin importar que hay disputa por el dinero desde el enfoque de Marketing), se "etiquetan" con sus productos en redes, interactúan con otros grupos sociales dentro y fuera de su localidad con la expectativa de alcanzar más clientes.

El cambio de tendencias en formas de invertir y de modalidad de venta online a través de redes sociales entre las que predominan Facebook, Whatsapp e Instagram, permite a las "Nenis" conectar directamente con el consumidor, identificando y satisfaciendo sus necesidades, preferencias, etc., reforzando con el uso de técnicas y frases persuasivas de ventas que transmiten calidez, atención y seguimiento al cliente, entre otros aspectos.

La "economía neni” gira alrededor de actividades orientadas al mercadeo, ya que las propias mujeres de estos grupos de negocios son "publicistas" en redes sociales, realizan transmisiones en vivo (ver Imagen 3) y subastas (ver Imagen 4), son creadoras de sus productos, agentes de ventas para negociar y cerrar pedidos, diseñadoras de su logística, mensajeras para servicios de entrega, etc.

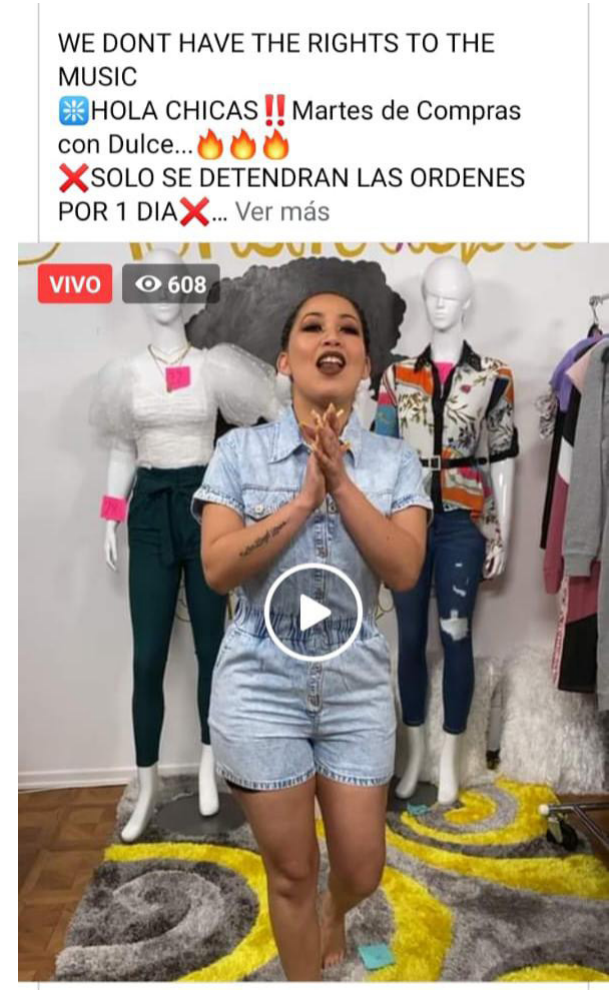

Imagen 3. Transmisión en vivo. 


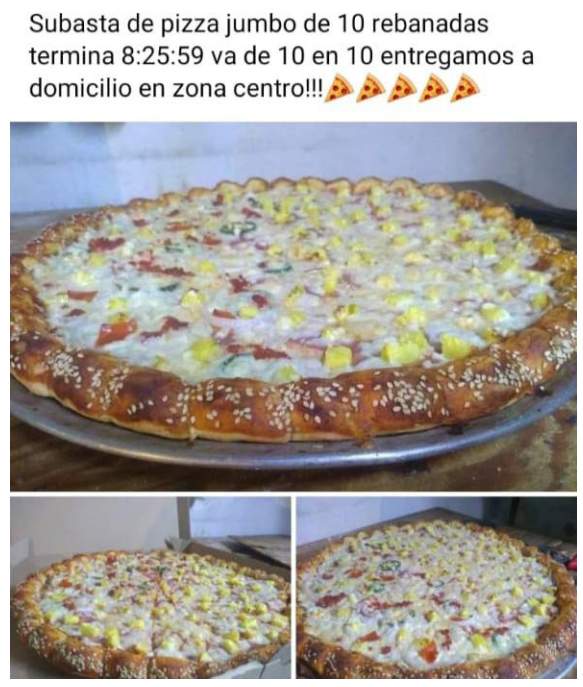

Imagen 4. Subasta de producto.

Su oferta de productos entre los que destacan alimentos y bebidas (preparadas en casa), ropa nueva o usada, joyería y cosméticos, accesorios para ambos sexos, son entregados en puntos específicos ya sea céntricos o intermedios con respecto a su lugar de residencia y el del cliente, o a completa conveniencia de éste último, incluyendo servicio a domicilio e incluso envíos a otras ciudades. Cabe señalar que a las "Nenis" que realizan envíos fuera de su localidad, se les ha catalogado en la categoría "premium".

Las "Nenis" poseen una gran capacidad de adaptación a los cambios, están deseosas de aumentar sus herramientas de productividad en el ámbito digital para continuar trabajando de forma independiente e incrementar sus habilidades asociadas a nuevas tecnologías de información.

\section{RECOMENDACIONES}

Entre los comentarios recopilados de la muestra, fue posible detectar las siguientes necesidades que se traducen en humildes propuestas para beneficio de la "economía neni":

- Capacitaciones en ventas y atención al cliente, a fin de incrementar sus ventas.

- Gestión de apoyos por parte del Gobierno para este grupo en particular, incorporación en proyectos específicos por categorías de productos, alineados a sus propios intereses como emprendedoras.

- Impulsar el crecimiento de sus microempresas "virtuales", para que se traduzcan en negocios que les permita tener una vida digna y decorosa, y no para sobrevivir solamente durante la pandemia actual; incluso, tienen la expectativa de generar empleos a más personas.

- Valoración del trabajo doméstico o de economía del cuidado que en la mayoría de los casos es efectuada por mujeres. Es decir, redistribución de responsabilidades en roles tradicionales, concientizar para una mayor participación masculina que vaya erradicando la cultura patriarcal y las brechas de género, ya que las mujeres dedican $66.6 \%$ de su tiempo al trabajo no remunerado de los hogares, el cual incluye el cuidado de la casa, niños, enfermos y adultos mayores (INEGIINMUJERES, 2020).

- Políticas públicas incluyentes de este grupo social, que coadyuven a un futuro próspero y con equidad de condiciones, ya que aunque se le ha catalogado en la polémica del "comercio informal", son una realidad latente en la República Mexicana. 


\section{REFERENCIAS}

1. ADN 40, (febrero 2021), Qué significa ser “"Nenis"”: cómo mujeres mexicanas buscan ganar dinero, https://www.adn40.mx/es-tendencia/nota/notas/2021-02-20-20-00/que-significa-ser"Nenis"-como-mujeres-mexicanas-buscan-ganar-dinero

2. Animal Político, (agosto 2020), Cómo ha impactado el COVID en la violencia contra las mujeres y cuál es la respuesta institucional, https://www.animalpolitico.com/2020/08/pandemia-violenciacontra-mujeres-respuesta-institucional/

3. Animal Político, (noviembre 2020), Octubre rompe récord de violencia familiar: hubo más de 20 mil denuncias en México, https://www.animalpolitico.com/2020/11/octubre-rompe-record-deviolencia-familiar-hubo-mas-de-20-mil-denuncias-en-mexico/

4. Asociación de emprendedores de México, Radiografía del emprendimiento en México 2020, https://drive.google.com/file/d/176S44oaRiPfSM2gnwfRZDh-YX3Yk4jsD/view

5. CEPAL, (febrero 2021), La autonomía económica de las mujeres en la recuperación sostenible y con igualdad, https://repositorio.cepal.org/bitstream/handle/11362/46633/5/S2000740_es.pdf

6. Debate, (febrero 2021), Quiénes son los “"Nenis"”, la nueva tendencia en redes, https://www. debate.com.mx/viral/Quienes-son-los-"Nenis"-la-nueva-tendencia-en-redes-20210220-0223.html

7. El Economista, (febrero 2021), Las "Nenis": autoempleo y comercio digital durante la pandemia, https://www.eleconomista.com.mx/empresas/Las-"Nenis"-autoempleo-y-comercio-digitaldurante-la-pandemia-20210225-0067.html

8. El Economista, (marzo 2021), Participación laboral femenina retrocedió a niveles del 2005, https://www.eleconomista.com.mx/empresas/Participacion-laboral-femenina-retrocedio-aniveles-del-2005-20210303-0008.html

9. El Economista, (noviembre 2020), Violencia contra las mujeres y el encierro durante la pandemia bloquean el desarrollo de la mujer: Equis Justicia, https://www.eleconomista.com.mx/politica/ Violencia-contra-las-mujeres-y-el-encierro-durante-la-pandemia-bloquean-el-desarrollo-de-lamujer-Equis-Justicia-20201122-0004.html

10. El Financiero, (marzo 2021), 'Economía neni'genera 9.5 millones de pesos al día por ventas en México, destaca la UNAM, https://www.elfinanciero.com.mx/economia/economia-neni-genera-95-millones-de-pesos-al-dia-por-ventas-en-mexico-destaca-la-unam

11. El Financiero, (marzo 2021), Mujeres ganan hasta 23\% menos que hombres si hay niños pequeños en casa, revela CEPAL, https://www.elfinanciero.com.mx/economia/mujeres-ganan-hasta-23menos-que-hombres-si-hay-ninos-pequenos-en-casa-revela-cepal

12. El Universal, (febrero 2021), ¿Quiénes son «las "Nenis"” y por qué hay tanta controversia en internet?, https://www.eluniversal.com.mx/de-ultima/que-es-una-neni-y-por-que-se-volvieronvirales

13. Empowering changemakers, https:/empowering-changemakers.eu/es/historydefinition-and-alternative-forms-of-social-entrepreneurship-es/https://concepto.de/ emprendimiento/\#: :text $=\mathrm{El} \% 20 \mathrm{t} \% \mathrm{C} 3 \% \mathrm{~A} 9 \mathrm{rmino} \% 20 \mathrm{emprendimiento} \% 20$ proviene $\% 20$ del,que $\% 20$ inicia\%20una\%20persona $\% 20$ o

14. Entrepreneur, (febrero 2021), ¿Qué son las «"Nenis"??, https://www.entrepreneur.com/ article/365827

15. Entrepreneur, Infografia: 6 tipos de emprendedores que existen, https://www.entrepreneur.com/ article $/ 265756$

16. Equis.org, (2020), Las dos pandemias, https://equis.org.mx/wp-content/uploads/2020/08/informedospandemiasmexico.pdf

17. Excelsior, (marzo 2021), Pandemia desató mayor violencia intrafamiliar en la Ciudad de México, https://www.excelsior.com.mx/comunidad/pandemia-desato-mayor-violencia-intrafamiliar-en-laciudad-de-mexico/1435926

18. Forbes, (julio 2020), Violencia doméstica contra la mujer aumenta $60 \%$ en México durante la pandemia, https://www.forbes.com.mx/women-violencia-mujer-hogar-aumenta-60-pandemia/

19. FRANCE.24, (marzo 2021), https://www.france24.com/es/programas/la-entrevista/20210303entrevista-cepal-mujeres-desempleo-pandemia? $\mathrm{ref}=\mathrm{tw}$

20. INEGI-INMUJERES, (octubre 2020), Encuesta nacional sobre el uso del tiempo, https://www. inegi.org.mx/contenidos/saladeprensa/boletines/2020/ENUT/Enut_Nal20.pdf

21. INMUJERES, (septiembre 2020), Cuatro causas que propician la brecha salarial de género, 
https://www.gob.mx/inmujeres/es/articulos/cuatro-causas-que-propician-la-brecha-salarial-degenero?idiom $=\mathrm{es}$

22. La Jornada, (marzo 2021), Las mujeres ganan en promedio $\$ 54.1$ menos que los hombres, https:// www.jornada.com.mx/notas/2021/03/07/economia/las-mujeres-ganan-en-promedio-54-1-menosque-los-hombres/

23. La-Lista, (marzo 2021), Radiografia de "las “Nenis"”, https://m.facebook.com/story.php?story_ fbid $=155152376436603 \& \mathrm{id}=100431071908734 \&$ sfnsn=scwspwa

24. Lifeder, Tipos de emprendimiento, https://www.lifeder.com/tipos-de-emprendimiento/

25. María Estela Raffino, (13 noviembre 2020), Concepto de emprendimiento,

26. Merca2.0, (marzo 2021), México es el país de Latinoamérica que está más lejos de cerrar la brecha salarial de género, https://www.merca20.com/mexico-es-el-pais-de-latinoamerica-queesta-mas-lejos-de-cerrar-la-brecha-salarial-de-genero/

27. Milenio, (febrero 2021), ¿Quiénes son 〈las "Nenis"'? Así nació la etiqueta viral que reivindicó a las mujeres emprendedoras, https://www.milenio.com/virales/"Nenis"-quienes-son-y-por-que-sellaman-asi-memes-virales

28. Milenio, (marzo 2021), En México, las mujeres ganan 12\% menos que los hombres, https://www. milenio.com/politica/desigualdad-salarial-mujeres-ganan-12-hombres

29. Observatorio de Igualdad de Género de América Latina y el Caribe-CEPAL, (febrero 2021), La autonomía económica de las mujeres en la recuperación sostenible y con igualdad, https://oig. cepal.org/es/documentos/la-autonomia-economica-mujeres-la-recuperacion-sostenible-igualdad

30. OCDE, (2020), Women at the core of the fight against COVID-19 crisis, https://www.oecd.org/ coronavirus/policy-responses/women-at-the-core-of-the-fight-against-covid-19-crisis-553a8269/

31. OCDE, (2021), COVID-19 is causing activity to collapse and unemployment to soar, http://www. oecd.org/employment-outlook

32. OCDE, (diciembre 2020), COVID-19 en América Latina y el Caribe: Consecuencias socioeconómicas y prioridades de política, http://www.oecd.org/coronavirus/policy-responses/ covid-19-en-america-latina-y-el-caribe-consecuencias-socioeconomicas-y-prioridades-depolitica-26a07844/\#section-d1e325

33. ONU, (febrero 2021), La pandemia del COVID-19 generó un retroceso de más de una década en los niveles de participación laboral de las mujeres en la región, https://coronavirus.onu.org. $\mathrm{mx} /$ la-pandemia-del-covid-19-genero-un-retroceso-de-mas-de-una-decada-en-los-niveles-departicipacion-laboral-de-las-mujeres-en-la-region

34. ONU-Mujeres, (2020), Violencia doméstica durante la COVID-19. Herramienta de orientación para empleadores, empleadoras y empresas, https://mexico.unwomen.org/es/digiteca/ publicaciones/2020-nuevo/junio-2020/violencia-domestica

35. PNUD-ONU, (noviembre 2020), ¿No hay lugar más seguro que el hogar?: El aumento en la violencia doméstica y de género durante los confinamientos por COVID-19 en ALC, https://www. latinamerica.undp.org/content/rblac/es/home/presscenter/director-s-graph-for-thought/no-saferplace-than-home---the-increase-in-domestic-and-gender-b.html

36. UNAM, (marzo 2021), "Economía neni" dinamiza el comercio digital en México, https://www. elfinanciero.com.mx/economia/economia-neni-genera-9-5-millones-de-pesos-al-dia-por-ventasen-mexico-destaca-la-unam

37. UNAM, (marzo 2021), Contundente salida de mujeres de la fuerza laboral a causa de la pandemia por COVID-19, https://unamglobal.unam.mx/contundente-salida-de-mujeres-dela-fuerza-laboral-a-causa-de-la-pandemia-por-covid-19/?fbclid=IwAR3R6OHUOGAK22xVWseE_4VcZQMtJUpsW4eEqD28MlpA-dqfybPoJErIkw

38. Universidad Anáhuac, (octubre 2019), Emprendimiento en México, https://www.anahuac.mx/ blog/emprendimiento-en-mexico\#: :text=La\%20Organizaci\%C3\%B3n\%20para\%201a\%20 Cooperaci\%C3\%B3n,del $\% 2052 \% 20 \% 25 \% 20 \mathrm{del} \% 20 \mathrm{PIB} \% 20$ nacional.

39. Uno TV, (febrero 2021), "Las "Nenis"”: ¿quiénes son y por qué se convirtieron en virales?, https://www.unotv.com/nacional/las-"Nenis"-quienes-son-y-por-que-se-convirtieron-en-virales/

40. Vanguardia.mx, (marzo 2021), La economía "neni" genera más de 9 mdp al día, según UNAM https://vanguardia.com.mx/articulo/la-economia-neni-genera-mas-de-9-mdp-al-dia-segun-unam 